study could have resulted from inadvertent introduction of CHD during umbilical catheterisation. However, the absence of such levels in other infants from Study B, who underwent invasive procedures, suggests that accidental introduction of CHD can be avoided and that the occasional use of an ethanol CHD solution for topical antisepsis in preterm infants need not result in high plasma CHD concentrations such as those encountered with prophylactic use.

There is no evidence that the presence of CHD in plasma is indicative of possible toxicity. In one study, designed to match one which demonstrated HCP neurotoxicity, CHD was detected in the liver, kidneys, and adipose tissue of newborn rhesus monkeys bathed regularly for 90 days in an $8 \%$ CHD detergent-based solution, but there was no clinical or histological evidence of toxicity and there was no detectable CHD in their brains. ${ }^{13}$ Four cases of accidental intravenous administration have been reported in human adults ${ }^{14}$ but with the exception of extensive haemolysis which occurred in 3 of them there were no toxic effects.

CHD would therefore appear to be of fairly low toxicity and of proved efficacy in reducing umbilical colonisation in the neonate. ${ }^{315}$ This study shows that significant percutaneous absorption of CHD is unlikely in term infants but may occur in preterm neonates treated with an ethanol solution of the antiseptic for cord care. This may however, be considerably reduced by avoiding the use of ethanol in the routine cord care of preterm infants.

Miss Lesley Cooper died on 15 April 1977.

We thank Mr J L Honigman for advice and help, Dr D R Harvey and Dr A P Norman for permission to study their patients, and $\mathrm{Mr} \mathrm{B}$ Holmes for measurement of chlorhexidine levels.

L V C was supported by a grant from Birthright and P J A by grants from the Medical Research Council and Rank Prize Fund.

\footnotetext{
References

1 Beeuwkes H. The use of chlorhexidine. Antonie van Leeuwenhoek 1958; 24 : 49-62.
}

${ }^{2}$ Lowbury E J, Lilly $\mathrm{H}$ A. Use of $4 \%$ chlorhexidine detergent solution (Hibiscrub) and other methods of skin disinfection. $\mathrm{Br}$ Med $\mathrm{J} 1973$; i: 510-5.

3 Alden V G, Burman D, Simpson R A, Fysh J, Gillespie W A. Comparison of hexachlorophene and chlorhexidine powders in prevention of neonatal infection. Arch Dis Child 1980; 55: 277-80.

4 Powell H C, Lampert P W. Hexachlorophene toxicity. In: Vinken P J, Bruyn G W, eds. Handbook of clinical neurology. Vol. 37. Amsterdam: North Holland, 1979: 479-509.

5 Tyrala E E, Hillman L S, Hillman R E, Dodson W E. Clinical pharmacology of hexachlorophene in newborn infants. $J$ Pediatr 1977; 91 : 481-6.

- Cowen J, Ellis S H, McAinsh J. Absorption of chlorhexidine from the intact skin of newborn infants. Arch Dis Child 1979; 54: 379-83.

7 Robinson R J. Assessment of gestational age by neurological examination. Arch Dis Child 1966; 41: 437-47.

8 Dubowitz L M S, Dubowitz V, Goldberg C. Clinical assessment of gestational age in the newborn infant. J Pediatr 1970; 77: 1-10.

9 Holmes B F. A note on hibitane assay with final iodination. Blood drugs and other analytical challenges. In: Reid E, ed. Methodological surveys in biochemistry. Vol. 7. Chichester: Ellis Horwood, 1978: 328-30.

10 Singer E J, Wegmann P C, Lehman M D, Christensen M S, Vinson L J. Barrier development ultrastructure and sulfhydryl content of the fetal epidermis. $J$ Soc Cosmet Chem 1971; 22: 119-37.

11 Nachman R L, Esterly N B. Increased skin permeability in preterm infants. $J$ Pediatr 1971 ; 79: 628-32.

12 Scheuplien R. Site variations in diffusion and permeability. In: Jarrett A, ed. The physiology and pathology of the skin. Vol. 5. The sweat glands, skin permeation lymphatics, the nails. New York: Academic Press, 1978 1731-52.

13 Case D E, McAinsh J, Rushton A, Winrow M J. Chlorhexidine: attempts to detect percutaneous absorption in man. In: Williams J D, Geddes A M, eds. Special problems in chemotherapy. New York: Plenum, 1976: 367-74.

14 ICI Limited, Pharmaceuticals Division. Unpublished reports 1981 .

15 George $\mathrm{R} H$. The effect of antimicrobial agents on the umbilical cord. In: Williams $\mathbf{J} \mathbf{D}$, Geddes $\mathrm{A} \mathbf{M}$, eds. Special problems in chemotherapy. New York: Plenum, 1976: 415-9.

Correspondence to Dr P J Aggett, Department of Physiology, Marischal College, Aberdeen AB9 1 AS.

Received 12 December 1980

\title{
Device for continuous urine collection in the newborn
}

\author{
R J LUND, H B VALMAN, AND ADAM PLATT \\ Department of Paediatrics, Northwick Park Hospital, Harrow
}

SUMMARY A device for the continuous collection of urine from newborn infants is described. This apparatus replaces the nursing tray of the Vickers 59 incubator.
Collection of urine in the newborn infant is notoriously difficult, especially if prolonged collection is required for either diagnostic or research purposes. Various methods previously used depend on modifications of urine or colostomy bags, which tend to 
cause skin irritation with repeated application. Leakage is a major problem and continuous aspiration, using a variety of negative pressure pumps, has been used with varying degrees of success to avoid this. ${ }^{1}$

Metabolic cages were initially designed for animal experiments to facilitate the collection of excreta. American incubators were first adapted to allow urine collections to be made from girls without the need for adhesive bags. ${ }^{2}{ }^{3}$ Winter et al. ${ }^{4}$ in 1967 and Lewis in $1977^{5}$ described further modifications of this method to be used for the collection of urine in children after the neonatal period.

We describe a further modification, which allows continuous collection of urine from babies nursed in Vickers 59 incubators. This is the standard incubator widely used in neonatal units in the UK. No adaptation of the incubator is needed because the device simply replaces the nursing tray and the incubator can be restored to normal use within a few minutes.

\section{The apparatus}

The apparatus measures $54 \times 34 \times 9 \mathrm{~cm}$ (Fig. 1). The two side plates extend for a further $8 \mathrm{~cm}$ and have a turned out flange at the base. This allows the device to be slid into grooves in the body of the incubator which normally house the nursing tray. It is secured by a spring-loaded brake and can be tilted, like the nursing tray, to facilitate drainage of urine or to position the infant. The urine collecting tray slopes inwards from an initial depth of $5 \mathrm{~cm}$, at an angle of $30^{\circ}$ before falling more steeply into a deeper trough from a point in the midline $17 \mathrm{~cm}$ from the head of the tray. From here it widens and deepens towards the foot board where it measures

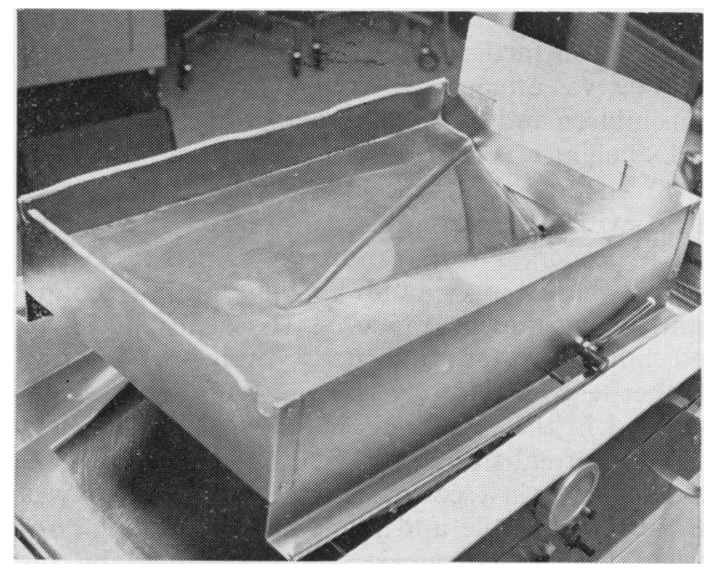

Fig. 1 The apparatus.
$24 \mathrm{~cm}$ wide and $12 \mathrm{~cm}$ deep. The central groove of the trough leads to a metal drainage pipe, to which is attached a flexible tube draining to a collecting bottle (Fig. 2).

There is a water-tight screw-on lid, which is fitted with an air release tube leading back to a point in the wall of the collecting tray above the drainage tube. The collecting bottle can be placed within a larger container and surrounded by dry ice to preserve any metabolites to be measured.

The infant is placed on a nylon mesh sling $(30 \times 20$ threads/inches ${ }^{2}$ ) suspended between two $1.5 \mathrm{~cm}$ diameter stainless steel rods which fit into notches in the foot and head plates of the tray. This mesh allows rapid transit of urine with only transient residual dampness, but retains stool and vomitus long enough to allow nursing staff to change the sling. If the infant has loose stools this selective drainage can be further facilitated by using a nappy liner under the infant's buttocks held in place with adhesive tape or Velcron. However, fluid stools will filter through and contaminate the urine collection. In boys urine is often projected beyond the confines of the apparatus. Therefore a Perspex heat shield is placed over the naked infant to intercept this stream and return it to the collecting tray with minimal loss. The shield also reduces radiation heat loss from small, naked infants.

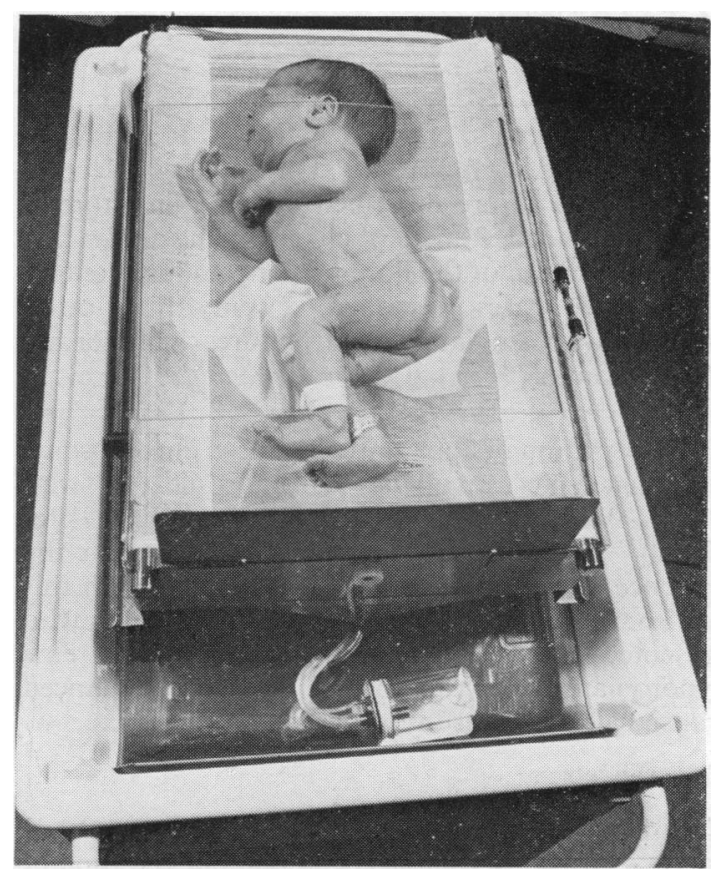

Fig. 2 The infant suspended in a nylon mesh sling. 
The daily urine output may be of low volume during the first few days of life especially in low birthweight infants. To lessen urine loss we apply silicone oil to all the drainage surfaces of the tray and scrape retained droplets of urine towards the drainage pipe using the rubber blade of a small window cleaner. Evaporative losses are reduced by nursing the child in humidified air.

There is no discomfort to the infant and the method is ethically and socially acceptable. Mothers can breast feed their infants under supervision, while any urine voided during the feed can be collected in a warmed receptacle placed under the female infant's buttocks, or positioned over the penis.

This device has greatly improved the accuracy and acceptability of prolonged urine collection for clinical and, especially, research purposes. The original model was constructed in stainless steel but it could be reproduced, in most research workshops, from a lighter and cheaper moulded plastic or Perspex.
We thank the Department of Medical Illustration for the photographs and Miss D Davis and Miss Rose-Marie Aikens for advice. The apparatus was constructed by Lawry Brice.

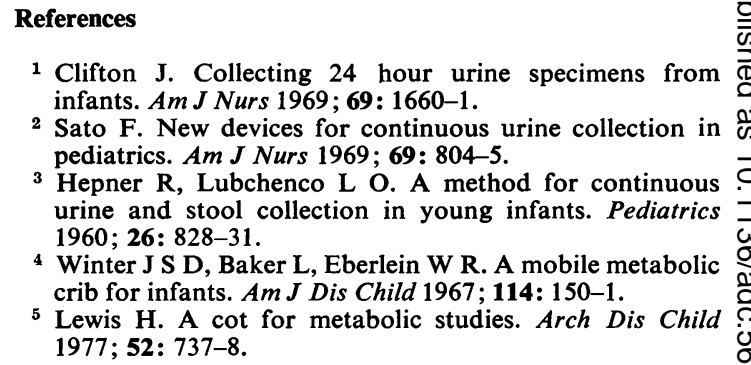

1 Clifton J. Collecting 24 hour urine specimens from infants. Am J Nurs 1969; 69: 1660-1.

2 Sato F. New devices for continuous urine collection in pediatrics. Am J Nurs 1969; 69: 804-5.

3 Hepner R, Lubchenco L O. A method for continuous urine and stool collection in young infants. Pediatrics 1960; 26: 828-31.

4 Winter J S D, Baker L, Eberlein W R. A mobile metabolic crib for infants. Am J Dis Child 1967; 114: 150-1.

5 Lewis H. A cot for metabolic studies. Arch Dis Child 1977; 52: 737-8.

Correspondence to Dr R Johan Lund, 125 2nd Avenue, Kenilworth 7700, Republic of South Africa.

Received 6 April 1981

\section{Chromosome 15 in floppy infants}

\section{A CAROLINE BERRY, ALISON J WHITTINGHAM, AND BRIAN G R NEVILLE}

\section{Prince Philip Research Laboratories, Paediatric Research Unit and Newcomen Centre, Guy's Hospital} Medical School, London

\begin{abstract}
SUMmary Three children with Prader-Willi syndrome and chromosome abnormalities affecting chromosome 15 are described and the literature is reviewed. The usefulness of chromosome analysis in the investigation of the floppy infant is illustrated by two of the cases described. Twenty-three other children with similar clinical features had normal chromosomes.
\end{abstract}

The association of apparently balanced chromosome rearrangements involving chromosome 15 with Prader-Willi syndrome has been reported previously ${ }^{1-5}$ We wish to describe for the first time the presence of a $Y / 15$ translocation in a boy with this syndrome, and we also wish to describe 2 girls who presented in the neonatal period with extreme hypotonia and who too were found to have balanced translocations of chromosome 15.

\section{Case reports}

Case 1. This was the first son of healthy, unrelated parents who were each aged 26 years at the time of his birth. He has one healthy brother and his mother has had no miscarriages, $\mathrm{He}$ was a term, breech delivery and weighed $2.7 \mathrm{~kg}$ at birth. He was noted to be very floppy as an infant and did not sit unaided until age 18 months. No information is available about early feeding habits but he started to gain excess weight at about 9 months. He has had surgery to correct strabismus of the right eye but has no other medical problems. When seen at age 8 years he was attending a residential school for ESN (M) children and was making reasonable progress.

His height was on the 10th centile and his weight of $80 \mathrm{~kg}$ on the 97th centile and he was grossly obese, with fat distributed mainly around his chest and abdomen. He had a moon-shaped face with almond-shaped eyes, and a slight antimongoloid slant to the palpebral fissures. His penis was small and buried in fat and the scrotum hypoplastic. Neither testis was descended and they could not be palpated in the inguinal canal. His hands and feet were of normal size and he had a tendency to genu valgum. When last seen at age $11 \frac{1}{2}$ years his height was on the 15th centile and his weight was being controlled by an 800 -calorie diet maintained by his residential school. 